\title{
Synthesis of New Phenolic-Schiff Base and Its Application as Antioxidant in Soybean Biodiesel and Corrosion Inhibitor in AISI 1020 Carbon Steel
}

\author{
Lucas F. Martins, ${ }^{a}$ Diana C. Cubides-Román, ${ }^{a}$ Vivian C. da Silveira, ${ }^{b}$ \\ Glória M. F. V. Aquije, ${ }^{c}$ Wanderson Romão, ${ }^{a, c}$ Reginaldo B. dos Santos, ${ }^{a}$ \\ Álvaro Cunha Neto ${ }^{a}$ and Valdemar Lacerda Jr. ${ }^{\circledR *, c}$
}
${ }^{a}$ Laboratório de Pesquisa e Desenvolvimento de Metodologias para Análise de Petróleos (LabPetro), Universidade Federal do Espírito Santo (UFES), Avenida Fernando Ferrari, 514, Goiabeiras, 29075-910 Vitória-ES, Brazil

${ }^{b}$ Departamento de Ciências Naturais, Centro Norte do Espírito Santo (CEUNES), Universidade Federal do Espírito Santo (UFES), 29932-540 São Mateus-ES, Brazil

'Instituto Federal do Espírito Santo (IFES), Av. Ministro Salgado Filho, Soteco, 29106-010 Vila Velha-ES, Brazil

\begin{abstract}
New Schiff base compound $N, N^{\prime}$-bis-(4-hexadecanate)-salicylethylenediamine (named IM) was synthesized, and characterized via infrared and nuclear magnetic ressonance spectroscopies. IM was tested as corrosion inhibitor and antioxidant in soybean biodiesel. Corrosion studies were developed with AISI 1020 carbon steel in a three-step accelerated corrosion assay and IM inhibitory activity was evaluated using microscopic techiniques: optical microscopy (OM), scanning electron microscopy (SEM) and atomic force microscopy (AFM). In $750 \mathrm{ppm}$ concentration, IM showed better inhibitory activity compared to commercial compounds tert-butylhydroquinone and pyrogallol, reducing root-mean-square roughness $(\mathrm{Rq})$ from 37.8 to $11.7 \mathrm{~nm}$ and peak-peak height (PP) from 454.1 to $120.2 \mathrm{~nm}$ after 8 days of immersion. Antioxidant studies were conducted using the PetroOXY equipment. In $250 \mathrm{ppm}$ concentration, IM showed better antioxidant activity as metal chelator, reducing biodiesel oxidation induced by copper on biodiesel. In this concentration, IM increased the induction period from 3.0 to $5.8 \mathrm{~h}$. Furthermore, the new Schiff base acts as an oxygen scavanger. This is a great property because it reduces oxygen concentration in biodiesel, reducing metal corrosion reactions.
\end{abstract}

Keywords: synthesis, Schiff base, biodiesel, antioxidant, corrosion inhibitor

\section{Introduction}

Biofuels are an alternate energy source, produced with the aim of reducing the consumption of fossil fuels. In this context, biodiesel appeared as a promising fuel of ignition compression engines. Biodiesel is defined as an ester mixture made from transesterification reactions between vegetable oils or/and animal fat and short-chain alcohols. It is considered a promising energy source because it is produced from renewable raw material, it is non-toxic and sulfur-free, in addition to having characteristics that are similar to those of petroleum diesel, like higher cetane number and no aromatics compounds. ${ }^{1}$

*e-mail: vljuniorqui@gmail.com
Despite being environmental-friendly, biodiesel has some problems that hinder its consumption: hydrolyses in the presence of moisture, wax and gum formation, carbon deposits on automotive components, difficulty starting the engine in cold weather, thermal and microbial decomposition and low oxidative stability. ${ }^{2,3}$ Among them, auto-oxidative reactions are a very concern problem, because ester molecules are degraded by systematic radical reactions, reducing biodiesel quality. ${ }^{4}$ Radical oxidative reactions occur because methylene hydrogens close to unsaturation are easily removable as radical hydrogens. ${ }^{5}$ Auto-oxidation reactions transform ester molecules into short alcohols, aldehydes, ketones, acids and insoluble products. ${ }^{3}$

Moreover, biodiesel is corrosive to some metals because of its hygroscopic nature and electric conductivity. ${ }^{6}$ Many 
researches report biodiesel's corrosion of aluminum, copper, brass, bronze and carbon stee ${ }^{7-11}$ and consequently, its corrosion of parts of the engine: cylinder lines, fuel tank, fuel pump, fuel lines and injector plunger. ${ }^{6,12}$ Biodiesel's corrosivity varies with the feedstock used in this production. ${ }^{13}$ Microbiologic corrosion has also been reported in association with biodiesel. ${ }^{14,15}$

Antioxidant compounds are added to biodiesel to increase its oxidative stability. Antioxidants are divided in two categories: primary antioxidants, which provide hydrogen radicals to break radical reactions at the propagation phase (also called chain-breakers); and secondary antioxidants, which act indirectly to reduce the formation of radicals, such as oxygen scavengers (react with oxygen in the medium) or metallic chelators (reacts with metallic ions). ${ }^{16,17}$ Corrosion can be reduced by the addition of corrosion inhibitors to biodiesel. These compounds adsorb on a metal surface, forming a protection layer that reduces corrosion reactions. It has been reported that organic compounds with $\pi$ electrons, aromatic rings and heteroatoms (specially nitrogen) have good inhibitory activity. ${ }^{18,19}$

The synthesis of new molecules is important to produce compounds that improve biodiesel's quality, to encourage its consumption. Schirmann et al. ${ }^{20}$ synthesized 3,3',5,5'-tetramethoxybiphenyl-4,4'-diol (TMBP) via enzymatic catalysis to improve the oxidative stability of soybean biodiesel. The Rancimat method (EN 14112) ${ }^{21}$ was used to evaluate biodiesel's stability and the synthetic compound was compared with commercial antioxidant 2,6-di-tert-butyl-4-methylphenol (BHT). In a $0.136 \mathrm{mmol} / 30 \mathrm{~g}$ concentration (antioxidant/biodiesel), TMBP increased the induction period from 3.67 to $6.67 \mathrm{~h}$, surpassing BHT (improved to $6.28 \mathrm{~h}$ ). Bär et al. ${ }^{22}$ produced hydrazide derived from BHT in a four-step synthesis and applied it as antioxidant to rapeseed biodiesel to improve the biofuel's stability from 8.08 to $10.25 \mathrm{~min}$ using the PetroOXY method (ASTM D7545). ${ }^{23}$

Many compounds with anticorrosive activity have been synthesized, but they are not directly applied to biodiesel. ${ }^{24-28}$ Some of these compounds are aromatic Schiff bases, which could be used as corrosion inhibitors because they contain conjugated unsaturation and heteroatoms. Soltani et al. ${ }^{29}$ synthesized two aromatic Schiff bases $N, N^{\prime}$-bis(salicylaldehyde)benzidine (SBA) and $N, N^{\prime}$-bis(5-nitrosalicyldiene)benzidine (SBB), to inhibit corrosion of carbon steel by acid. In a $1 \mathrm{mmol} \mathrm{L}^{-1}$ concentration, SBA and SBB had 93.8 and $95.4 \%$ of inhibitory efficiency, respectively. Benbouguerra et al. ${ }^{30}$ investigated the corrosion of carbon steel using a new Schiff base molecule (E)- $N, N$-dimethyl-4-((phenylimino)methyl) aniline ( $E$-NDPIMA) via weight loss measurements, having found that this compound inhibits corrosion in $85.83 \%$ at a $10^{-3} \mathrm{~mol} \mathrm{~L}^{-1}$ concentration.

Some molecules have been synthesized and studied to improve at least two properties of biodiesel, the so-called multifunctional molecules. ${ }^{31}$ Singh et al..$^{32}$ synthesized a hindered phenolic Schiff base for biolube and Jatropha curcas, which improves the lubricity and oxidative stability of biodiesel. Molecules with antioxidant and NOx reduction activity, ${ }^{33}$ as well as with anticorrosive and acidity reduction properties may be found in the literature, ${ }^{34,35}$ but no work testing new synthetic molecules with antioxidant and anticorrosive activities in biodiesel has been conducted. In this work we synthesized a new Schiff base molecule ( $N, N^{\prime}$-bis-(4-hexadecanate)-salicylethylenediamine, IM) and tested it as corrosion inhibitor on AISI 1020 carbon steel immersed in soybean biodiesel using optical microscopy (OM), scanning electron microscopy (SEM) and atomic force microscopy (AFM) to evaluate inhibition activity. Also, we tested the new molecule as antioxidant in biodiesel contaminated with copper(II) acetate, using the PetroOXY method.

\section{Experimental}

Materials and reagents

2,4-Dihydroxybenzaldhyde (98\%, Sigma-Aldrich, St. Louis, United States), $N, N$ '-dicyclehexylcarbodiimide (99\%, Sigma-Aldrich, St. Louis, United States), dimethylaminopyridine (99\%, Sigma-Aldrich, St. Louis, United States), ethylenediamine (99\%, Vetec, Duque de Caxias, Brazil), acetic acid glacial (97\%, Alphatec, São Bernardo do Campo, Brazil), hexadecanoic acid (98\%, Vetec, Duque de Caxias, Brazil), sodium bicarbonate (99.5\%, Alphatec, São Bernardo do Campo, Brazil), sodium chlorate (99\%, Cinética, Jandira, Brazil), chloroform (99.8\%, Vetec, Duque de Caxias, Brazil), ethanol (99.8\%, Vetec, Duque de Caxias, Brazil), hexane (99.9\%, Neon, São Paulo, Brazil) and ethyl acetate $(99.5 \%$, Vetec, Duque de Caxias, Brazil) were used to organic syntheses and produce purification. Biodiesel was synthesized with methanol (99\%, Dinâmica, Indaiatuba, Brazil), sodium hydroxy (97\%, Vetec, Duque de Caxias, Brazil) and soybean oil puchased at a local market. Copper(II) acetate monohydrate (98\%, Sigma-Aldrich, St. Louis, United States) was used to contaminate biodiesel in oxidation experiments.

\section{Spectroscopic characterization instruments}

${ }^{1} \mathrm{H}$ and ${ }^{13} \mathrm{C}$ nuclear magnetic ressonance spectra (NMR) were obtained using a Varian VNMRS400 spectrometer, 
with a magnetic field of $9.4 \mathrm{~T}, 32$ scans for ${ }^{1} \mathrm{H}$ spectra and 2000 scans for ${ }^{13} \mathrm{C}$ spectra, and deuterated chloroform $\left(\mathrm{CDCl}_{3}\right)$ as solvent. The infrared spectra (IR) were acquired using the Agilent Cary 630 FTIR spectrometer with 32 scans.

\section{Synthesis}

The organic synthesis was conducted in two steps, as shown in Figure 1. First, 4-formyl3-hydroxyphenylhexadecanate (ES) was synthesized by following the Steglich methodology. Hexadecanoic acid $(10 \mathrm{mmol})$ was solubilized in $15 \mathrm{~mL}$ chloroform and dicyclohexylcarbodiimide (DCC, $11 \mathrm{mmol}$ ) and 4-dimethylaminopyridine (DMAP, $0.5 \mathrm{mmol}$ ) were added to the solution, both in solid state. The solution was stirred for $30 \mathrm{~min}$ at room temperature to produce hexadecanoic anhydrede. Then, 2,4-dihydroxybenzaldehyde (10 mmol) was added to the solution and the reaction was carried out at room temperature for $12 \mathrm{~h}$. The by-product was filtered out under suction, the organic layer was washed with saturated $\mathrm{NaHCO}_{3}$, and the brine solutions and solvent were removed via rotoevaporation. The crude product was purified via column chromatography over $\mathrm{SiO}_{2}$ by eluating a solvent mixture of hexane/ethyl acetate (v/v, 95:5) and the product obtained was a white solid. The second step consisted in the synthesis of $N, N^{\prime}$-bis-(4-hexadecanate)salicylethylenediamine (IM) via Schiff base formation. ES $(5 \mathrm{mmol})$ was solubilized in $50 \mathrm{~mL}$ ethanol and lightly acidified with glacial acetic acid $(0.5 \mathrm{mmol})$, and this solutions was strirred for $15 \mathrm{~min}$ at room temperature. Then, ethylenediamine $(2.5 \mathrm{mmol})$ was added as a liquid and the reaction was carried out under reflux for $4 \mathrm{~h}$. The yellow crude product was filtered out under suction, washed with cold ethanol, recrystalized from an ethanol/chloroform solution (v/v, 1:1) and dried with a vacuum desiccator.

\section{4-Formyl-3-hydroxyphenylhexadecanate (ES)}

mp 56-57 ${ }^{\circ} \mathrm{C}$; IR v / $\mathrm{cm}^{-1} 3193,2953,2916,2848$, $1754,1680,1623,1576,1488,1461,1380,1285,1214$,
1164, 1133, 1093, 981, 883, 813, 718; ${ }^{1} \mathrm{H}$ NMR (400 MHz, $\left.\mathrm{CDCl}_{3}\right) \delta 0.89\left(\mathrm{t}, 3 \mathrm{H}, J 7.05 \mathrm{~Hz}, \mathrm{CH}_{3}\right), 1.25\left(\mathrm{~s}, 28 \mathrm{H}, \mathrm{CH}_{2}\right)$, $1.74\left(\mathrm{~m}, 2 \mathrm{H}, \mathrm{CH}_{2}\right), 2.56$ (t, 2H, J 7.5 Hz, $\left.\mathrm{CH}_{2}\right), 6.74$ (s, 1H, H-Ar), 6.77 (d, 1H, J $8.40 \mathrm{~Hz}, \mathrm{H}-\mathrm{Ar}), 7.56$ (d, 1H, $J 8.40 \mathrm{~Hz}, \mathrm{H}-\mathrm{Ar}$ ), 9.85 (s, 1H, $\underline{\mathrm{HCO}}$ ), 11.20 (s, 1H, OH); ${ }^{13} \mathrm{C} \mathrm{NMR}\left(100 \mathrm{MHz}, \mathrm{CDCl}_{3}\right) \delta 14.1,22.6,29.0,29.2,29.3$, 29.4, 29.5, 29.6, 29.6, 29.6, 29.6, 29.7, 31.9, 34.4, 110.5, $113,8,118.5,134.8,157.4,163.1,195.4$.

$N, N$-Bis-(4-hexadecanate)-salicylethylenediamine (IM)

mp 129-130 ${ }^{\circ} \mathrm{C}$; IR v / $\mathrm{cm}^{-1} 2954,2914,2847,2648$, 2110, 1892, 1753, 1634, 1579, 1499, 1464, 1407, 1381, $1265,1230,1162,1135,1032,980,913,873,845,818,762$, 719; ${ }^{1} \mathrm{H}$ NMR $\left(400 \mathrm{MHz}, \mathrm{CDCl}_{3}\right) \delta 0.87$ (t, 3H, J $7.05 \mathrm{~Hz}$, $\left.\mathrm{CH}_{3}\right), 1.25\left(\mathrm{~s}, 28 \mathrm{H}, \mathrm{CH}_{2}\right), 1.72\left(\mathrm{~m}, 2 \mathrm{H}, \mathrm{CH}_{2}\right), 2.53(\mathrm{t}, 2 \mathrm{H}$, $\left.J 7.55 \mathrm{~Hz}, \mathrm{CH}_{2}\right), 3.90\left(\mathrm{~s}, 2 \mathrm{H}, \mathrm{N}-\mathrm{CH}_{2}\right), 6.59(\mathrm{dd}, 1 \mathrm{H}, J 2.22$, $8.36 \mathrm{~Hz}, \mathrm{H}-\mathrm{Ar}), 6.66$ (d, 1H, J $2.22 \mathrm{~Hz}, \mathrm{H}-\mathrm{Ar}), 7.21$ (d, 1H, $J 8.40 \mathrm{~Hz}, \mathrm{H}-\mathrm{Ar}), 8.31$ (s, 1H, HO), 9.85 (s, $1 \mathrm{H}, \underline{\mathrm{HCN}}$ ); ${ }^{13} \mathrm{C} \mathrm{NMR}\left(100 \mathrm{MHz}, \mathrm{CDCl}_{3}\right) \delta 14.1,22.6,24.8,29.0,29.2$, 29.3, 29.4, 29.5, 29.6, 29,7, 31.9, 34.4, 59.4, 110.3, 112.3, $116.4,132.3,153.9,162.5,165.8,171.1$.

\section{SEM, OM and AFM}

Scanning electron microscopy (SEM) microimages of the metallic surface were taken with ZEISS Sigma 300 (Oxford instruments, Germany), operating at $20 \mathrm{kV}$, with $8.5 \mathrm{~mm}$ work distance and $1000 \times$ magnification. Optical microscopy (OM) and atomic force microscopy (AFM) microimages were taken with an Alpha 300R confocal microscope (WITec, Germany) in non-contact mode, with $0.6 \mathrm{~Hz}$ scanning frequency, $10 \times 10 \mu \mathrm{m}$ scanning size. To evaluate the roughness of the AFM topographic images, peak-peak height (PP) and roat-mean-square roughness $(\mathrm{Rq})$ were used. PP is defined as the sum of the higest peak height with the absoulte value of the lowest valley depth (equation 1) and $\mathrm{Rq}$ is the standart deviation of surface heights (equation 2). The equations are described as follows:

$$
\mathrm{PP}=\max \mathrm{z}(\mathrm{N}, \mathrm{M})-|\min \mathrm{z}(\mathrm{N}, \mathrm{M})|
$$

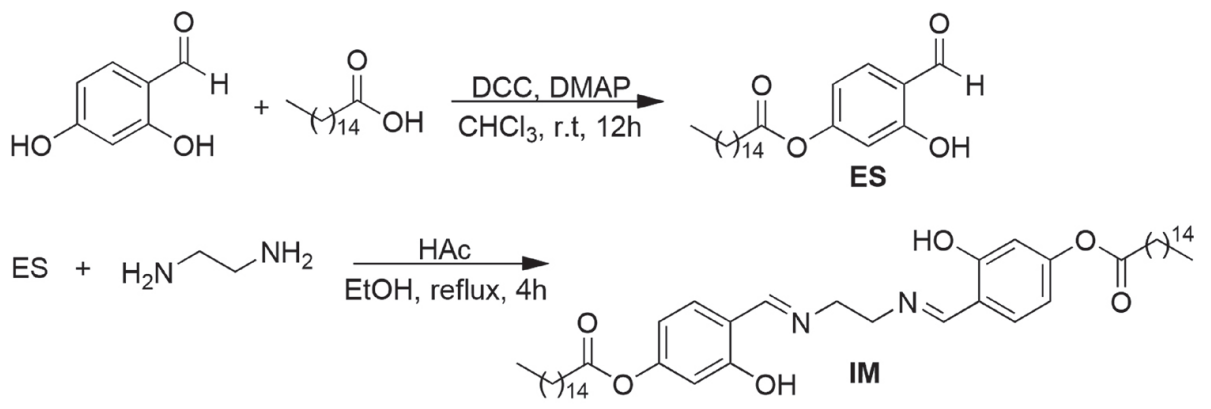

Figure 1. Synthetic route of IM. 
$\mathrm{Rq}(\mathrm{N}, \mathrm{M})=\sqrt{\frac{1}{\mathrm{MN}} \sum_{\mathrm{x}=1}^{\mathrm{N}} \sum_{\mathrm{y}=1}^{\mathrm{M}}(\mathrm{z}(\mathrm{x}, \mathrm{y})-\overline{\mathrm{z}}(\mathrm{N}, \mathrm{M}))^{2}}$

where $\mathrm{N}$ and $\mathrm{M}$ are the image's dimensions and domain of the $\mathrm{x}$ and $\mathrm{y}$ axis, respectively, $\mathrm{z}$ is the height of the point on the image and $\bar{z}$ is the arithmetic average height. The greater the difference between initial the value and final value, the more harmful the corrosive process was.

\section{Biodiesel's oxidative stability}

The period induction of biodiesel was obtained using the Petrotest PetroOXY equipment (Petrotest, Germany) operated in accordance with ASTM D7545. ${ }^{23} 5 \mathrm{~mL}$ of sample were placed in a hermetically sealed vessel. The system was pressurized with oxygen up to $700 \mathrm{kPa}$ and then heated up to $140{ }^{\circ} \mathrm{C}$. Heating rises the internal pressure up to a certain maximum value. The high temperature and high pressure stimulate biodiesel's oxidation reactions, forming free radicals that react with oxygen, reducing the system's internal pressure. The time it takes from the start of the heating process to the $10 \%$ decrease in the maximum pressure is called the induction period (IP). The value was converted to the unit used in the Rancimat method, as described in equation 3.

$\mathrm{IP}_{\text {Rancimat }}=\left(\mathrm{IP}_{\text {PetroOXY }} \times 20\right) / 60$

\section{Accelerated corrosion assay}

AISI carbon steel coupons with $2.7 \times 1.2 \times 0.1 \mathrm{~cm}$ dimensions were abraded using 180, 220, 320, 400, 600 and 1200 grade $\mathrm{SiC}$ emery paper. A hole with $0.2 \mathrm{~cm}$ diameter was made for the immersion. All coupons were washed with deionized water, degreased with acetone and dried in hot air. After dried, the coupons were immediately immersed in biodiesel. The accelated corrosion assay was conducted at $60{ }^{\circ} \mathrm{C}$ in an enclosed space. The soybean biodiesel was synthesized via basic transestecification, and catalyzed by $\mathrm{NaOH}$, in a 9:1 molar ratio of methanol and soybean oil. ${ }^{36}$

The experiment was divided into three steps. First, we studied in which day the corrosion reactions caused the most significant superficial change to the coupon's surface, comparing consecutive days. For that, the alteration of biodiesel's stability and the superficial alterations of the coupons' surface were evaluated. Biodiesel's degradation after 2-14 days under the experimental conditions was evaluated based on the induction period (IP) values, by immersing the coupons in soybean biodiesel for 4-12 days. After immersion, the coupons were washed with ethanol and acetone (to remove biodiesel and some loosely bonded corrosion products), dried with hot air and then analyzed using microscopic techniques.

In the second step, we evaluated the regression of the carbon steel coupons' corrosion inducted by their immersion in biodiesel with IM in 250, 500, 750 and $1000 \mathrm{ppm}$ concentrations, for the time stipulated in the first step. In this accelerated experiment, IM is completely soluble in soybean-oil biodiesel at these concentrations. Finaly, in the third step, we compared IM's anticorrosive activity with commercial biodiesel additives tert-butylhydroquinone (TBHQ) and pyrogallol (PY) by immersing the coupons in biodiesel with related compounds, at the concentration and for the immersion period stipulated in the first and second steps.

\section{Antioxidant activity}

IM's antioxidant activity was tested in biodiesel contaminated with copper(II) acetate monohydrate in a $200 \mathrm{ppm}$ concentration. For this, $10 \mathrm{~mL}$ of biodiesel (with and without IM) were heated up to $60{ }^{\circ} \mathrm{C}$ in a $50 \mathrm{~mL}$ Erlenmeyer, and after thermal stability had been reached, copper(II) acetate monohydrate was added. After $30 \mathrm{~s}$, the biodiesel/copper mixture was filtered and the induction period was obtained using the PetroOXY equipment. IM was used at the same concentrations of the corrosion test. The same procedure was repeated for biodiesel free of contaminants, to understand how the compound influences biodiesel's induction period under the experimental conditions.

\section{Results and Discussion}

\section{Synthesis}

In the precursor synthesis (ES), the hydroxyl in the ortho position in 2,4-dihydroxybenzaldhyde is less reactive due to the hydrogen bond between hydroxyl's hydrogen and carbonyl's oxygen, and the reaction is favored when hydroxyl is in the para position. ${ }^{37,38}$ The infrared spectra shows two carbonyl bands (1680 and $1754 \mathrm{~cm}^{-1}$ ) referring to aldehyde and ester, respectively. The proton nuclear magnetic resonance shows signs of hydrogens belonging to alpha $(2.56 \mathrm{ppm})$ and beta $(1.74 \mathrm{ppm})$ carbonyl methylenes, aldehyde's hydrogen $(9.85 \mathrm{ppm})$ and hydroxyl's hydrogen (11.20 ppm). The Schiff base compound (IM) was obtained as a light-yellow powder, with a $60 \%$ yield. The spectroscopy techniques confirmed the imine molecule's structure: the infrared spectra showed the $\mathrm{C}=\mathrm{N}$ axial deformation band at $1634 \mathrm{~cm}^{-1}$; the proton nuclear magnetic resonance spectra showed singlet peaks 
at 3.91 and $8.32 \mathrm{ppm}$, assigned to methylene hydrogens between $\mathrm{C}=\mathrm{N}$ bonds and hydrogen bonded to imine carbon, respectively; and a 68.3 ppm peak was noticed in the carbon nuclear magnetic resonance spectra, attributed to iminic carbon. All spectral data of the products' characterization may be found in the Supplementary Information section.

\section{Accelerated corrosion assay}

Fisrtly, we studied biodiesel's degradation at $60{ }^{\circ} \mathrm{C}$ during 14 days, as well the evolution of AISI 1020 carbon steel's corrosion after 4, 6, 8, 10 and 12 days to discover when the most significant superficial change of the metal coupons' surface occurs. The experiment's temperature was chosen based on the fuel system's operating temperature, which varies between 40 and $90{ }^{\circ} \mathrm{C} .{ }^{39} \mathrm{As}$ it was an enclosed system, the corrosion reactions occurred due to the moisture and dissolved oxygen already present in biodiesel. ${ }^{40,41}$

The induction period (IP) is a stability parameter that is widely applied in biodiesel oxidation studies. ${ }^{3,17,42}$ Figure 2 shows the IP's downward trend as the days go by. At the beginning, the induction period was above the EN $14112^{21}$ limit. After 8 days, the induction period dropped to $2.53 \mathrm{~h}$, and its pattern remained the same from the eighth day until the fourteenth day, indicating biodiesel's total oxidation. The increase in temperature accelerated biodiesel's oxidation reactions, forming smaller chain compounds (acids, alcohol, aldehydes, ketones, peroxydes...), Diels-Alder dimers and gums. ${ }^{3,40,41}$ Furthermore, biodiesel's acid degradation products are reported as harmful to the increase in corrosion reactions..$^{7,12,41,43} \mathrm{Jin}$ et al.$^{44}$ evaluated mild carbon steel corrosion inducted by palm biodiesel at 27,50 and $80^{\circ} \mathrm{C}$, having found that the total acid number (TAN) and corrosion rate increase with temperature.

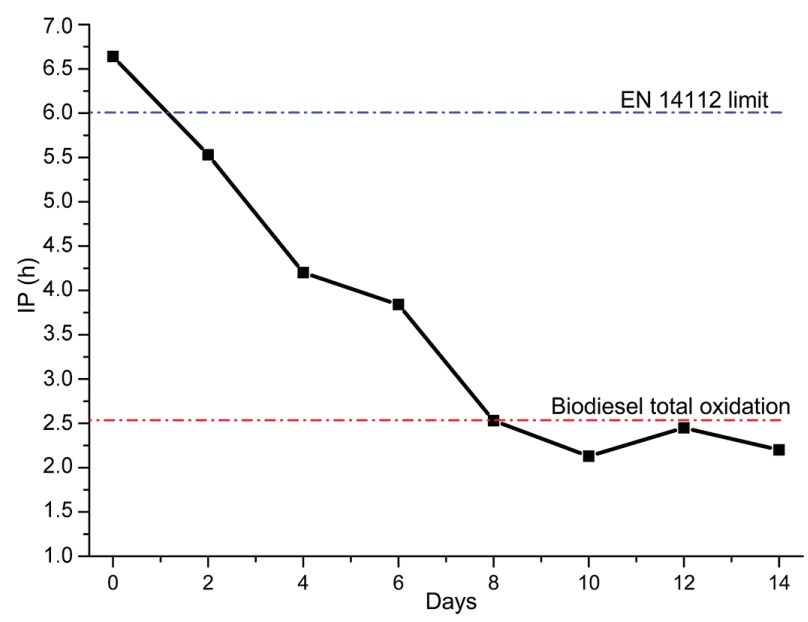

Figure 2. Induction period (in hours) of soybean biodiesel at $60{ }^{\circ} \mathrm{C}$ for 14 days.
Figure 3 shows the OM, SEM and AFM microimages before immersion (Figures 3a-3c) and after all periods of immersion (Figures 3d-3r) in biodiesel. The AFM data (roughness parameters) obtained from this step are presented in Table 1. After four days of immersion no superficial change is noticeable in the microimages. However, increases in the roughness parameters' values, compared to the superficial values before immersion, show that corrosion had already occurred in this period. PP and Rq increased from 47.6 to $166.6 \mathrm{~nm}$ and from 6.7 to $18.7 \mathrm{~nm}$, respectively. The increase in the PP value indicates that deeper pits or deposits have been formed, and the increase in the Rq value indicates that the surface is more irregular. ${ }^{45,46}$

From the sixth day on, pit corrosion may be noticed in the $\mathrm{OM}$ and MEV images (Figures 3g and 3h). After 8 days of immersion, the roughness parameters reach their maximum values: $\mathrm{PP}=454.1 \mathrm{~nm}$ and $\mathrm{Rq}=37.8 \mathrm{~nm}$. Furthermore, the AFM images reveal crevice corrosion from the eighth day on (Figure 31). This type of corrosion occurs inside fissures, in this case, formed by polishing silicon carbide paper during the samples' preparation. The observations made after 4 and 8 days of corrosion corroborate that AFM is a highly-advanced microscopy technique, due to the acquired data providing images with higher resolution and numeric topographic profile parameters. ${ }^{47-49}$

After 10 days, the parameters' values decrease, but the number and size of the pits increases until the twelfth day. The regression of the PP and Rq values can be explained by the sealing of the pits. The growth up to a maximum value and subsequent decrease in the roughness indices was also observed by Dias et al. ${ }^{49}$ At the last day, the OM and SEM images show larger pits and greater deposition of corrosion products (Figures $3 p$ and $3 q$, respectively). Based on the analysis of the images and parameters, it was decided that the most significant superficial change occurred on the eighth day of immersion, due to the appearance of crevice corrosion and to the highest $\mathrm{Rq}$ and $\mathrm{PP}$ values having been observed on this day. This was the same period when biodiesel achieved its maximum oxidation (Figure 2). This observation confirms that biodiesel becomes more corrosive as it becomes more degraded. ${ }^{43}$

The second step determined the optimum IM concentration in biodiesel, to reduce corrosion damages on carbon steel's surface during the pre-studied time of immersion (8 days) in biodiesel mixed with IM at the following concentrations: 250, 500, 750 and $1000 \mathrm{ppm}$. Figure 4 shows AFM microphotos of the surfaces of the coupons immersed in biodiesel with different IM concentrations for 8 days. Pit and crevice corrosion was observed in all coupons, as indicated by the arrows. The 

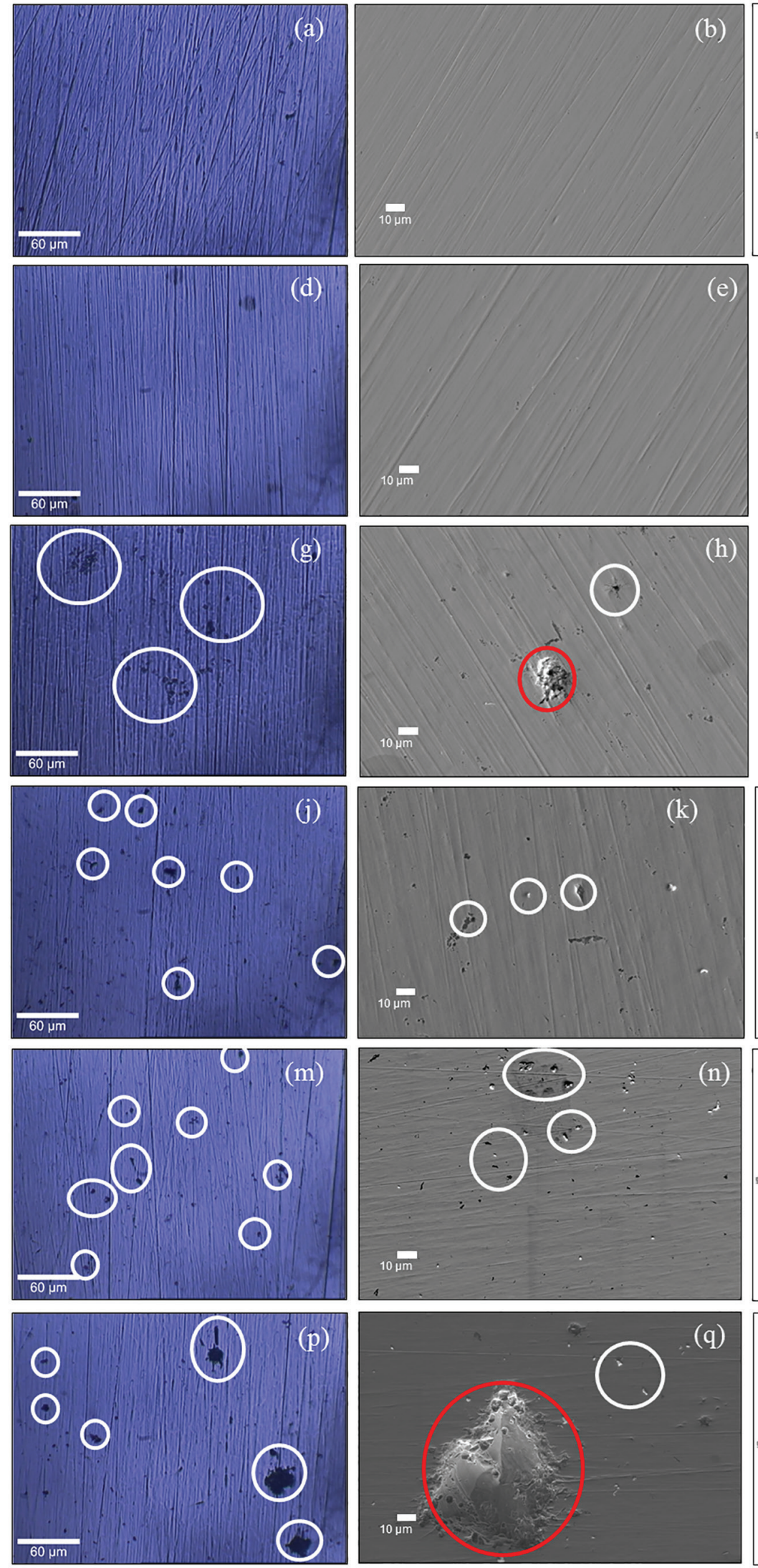
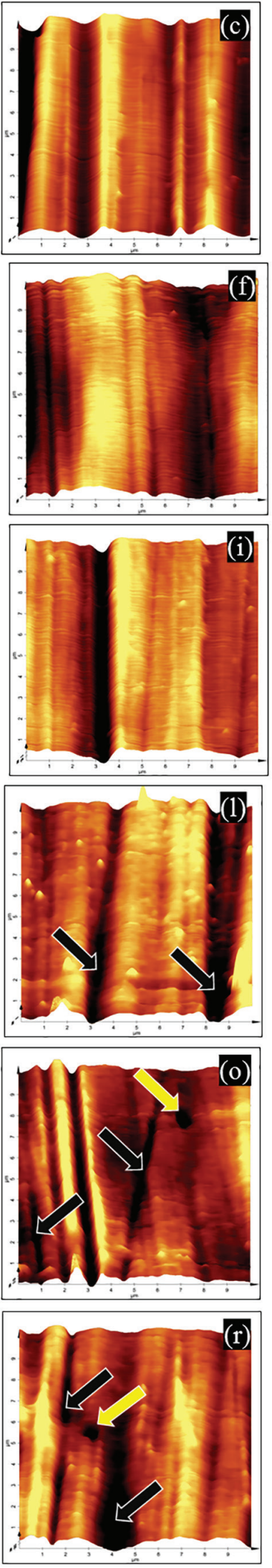

Figure 3. OM, SEM and AFM images of AISI 1020 carbon steel coupon's surface before (a-c) and after 4 days (d-f), 6 days (g-i), 8 days (j-1), 10 days $(\mathrm{m}-\mathrm{o})$ and 12 days (p-r) of immersion in biodiesel. In each row, the white and red circles in the OM and SEM images indicate pit corrosion and deposition of corrosion products, respectively. The black and yellow arrows in the AFM images indicate crevice and pit corrosion, respectively. 
Table 1. AFM topographic parameters of the AISI 1020 carbon steel coupon's surface before and after immersion in biodiesel at $60{ }^{\circ} \mathrm{C}$

\begin{tabular}{lccccc}
\hline Immersion period & Before immersion & 4 days & 6 days & 8 days & 10 days \\
\hline $\mathrm{PP}^{\mathrm{a}} / \mathrm{nm}$ & 47.6 & 166.6 & 153.7 & 454.1 & 140.3 \\
$\mathrm{Rq}^{\mathrm{b}} / \mathrm{nm}$ & 6.7 & 18.7 & 26.4 & 37.8 & 16.1 \\
\hline
\end{tabular}

aPeak-peak heigth; ${ }^{b}$ root-mean-square roughness.

parameters obtained via AFM are shown in Table 2. In the blank coupon (8 days of immersion), $\mathrm{Rq}$ increased from 6.7 to $37.8 \mathrm{~nm}$ and PP increased from 47.6 to $454.1 \mathrm{~nm}$ (Table 1). Comparing Tables 1 and 2, the Rq and PP values of the coupons immersed in the IM/biodiesel solution are smaller than the blank coupon's. Between them, the coupon immersed in $750 \mathrm{ppm} \mathrm{IM/biodiesel} \mathrm{has} \mathrm{the} \mathrm{lowest} \mathrm{Rq} \mathrm{and}$ PP values: 11.7 and $120.2 \mathrm{~nm}$, respectively. Inhibitory activity was expected because IM has heteroatoms, $\pi$ electrons and a long aliphatic side chain, which are specific features of corrosion inhibitors. ${ }^{18,50,51}$ The reduction in the roughness parameters values indicates the inhibition of corrosion reactions, according to Jakeria et al..$^{52}$

In the third step, IM's inhibition activity was compared to two commercial antioxidant compounds that are widely used in biodiesel: pyrogallol (PY) and tert-butylhydroquinone (TBHQ). ${ }^{3,53,54}$ These three componds were used at $750 \mathrm{ppm}$ during 8 days of immersion. Figure 5 shows microscopic images of the coupons' surface in this step. In the OM images (Figures 5a-5c), the coupon immersed in biodiesel
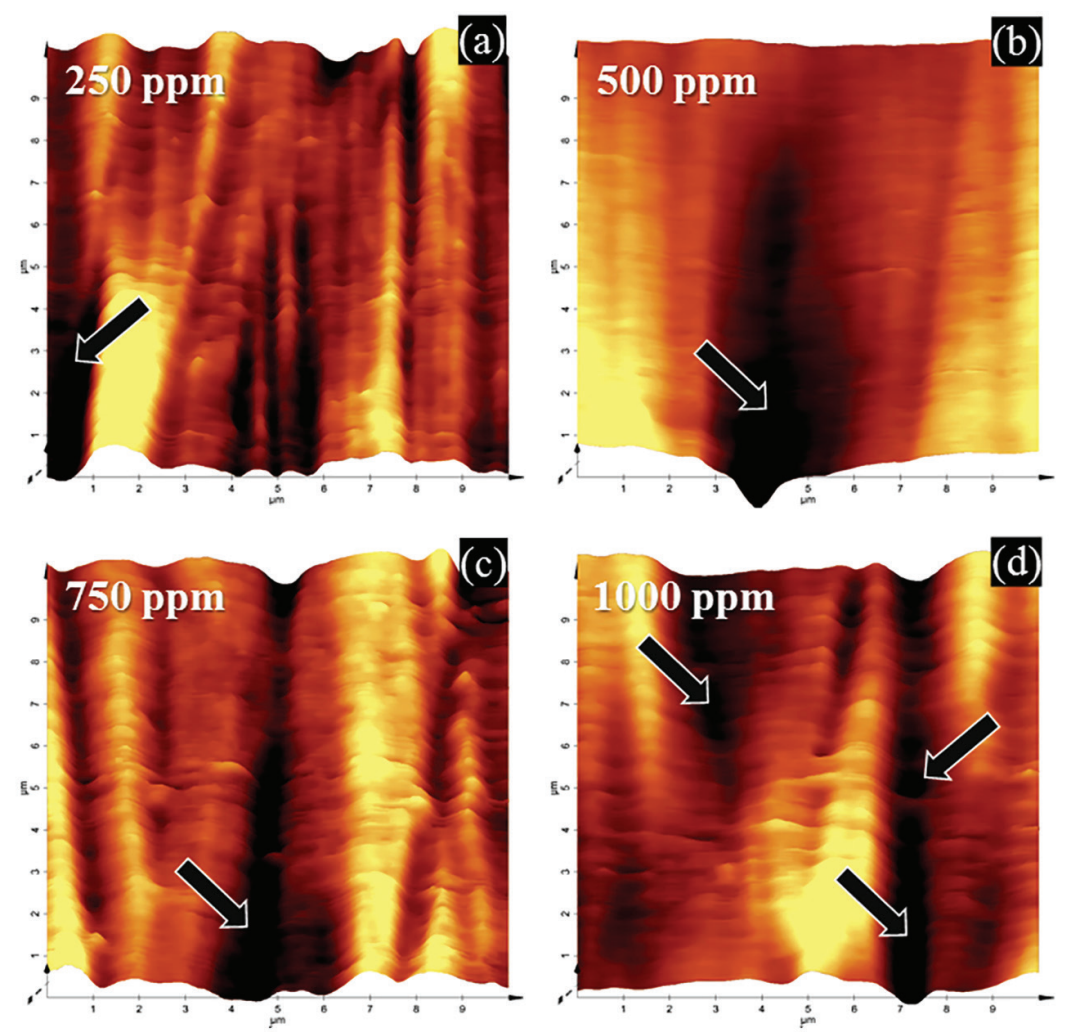

Figure 4. AFM microimages of the coupons' surface after immersion at biodiesel with IM in (a) 250; (b) 500; (c) 750 and (d) 1000 ppm concentrations.

Table 2. AFM topographic parameters of the AISI 1020 carbon steel coupon's surface after immersion in biodiesel at $60{ }^{\circ} \mathrm{C}$ with IM at $250,500,750$ and 1000 ppm concentrations, TBHQ and PY, both at 750 ppm concentration

\begin{tabular}{lcccccc}
\hline & IM & IM & IM & IM & TBHQ & PY \\
\cline { 2 - 7 } & $250 \mathrm{ppm}$ & $500 \mathrm{ppm}$ & $750 \mathrm{ppm}$ & $1000 \mathrm{ppm}$ & $750 \mathrm{ppm}$ & $750 \mathrm{ppm}$ \\
\hline $\mathrm{PP}^{\mathrm{a}} / \mathrm{nm}$ & 173.3 & 243.8 & 120.2 & 136.0 & 140.2 & 167.1 \\
$\mathrm{Rq}^{\mathrm{b}} / \mathrm{nm}$ & 16.5 & 12.9 & 11.7 & 15.6 & 15.6 & 16.2 \\
\hline
\end{tabular}

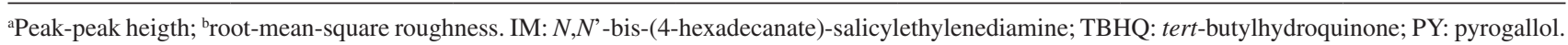



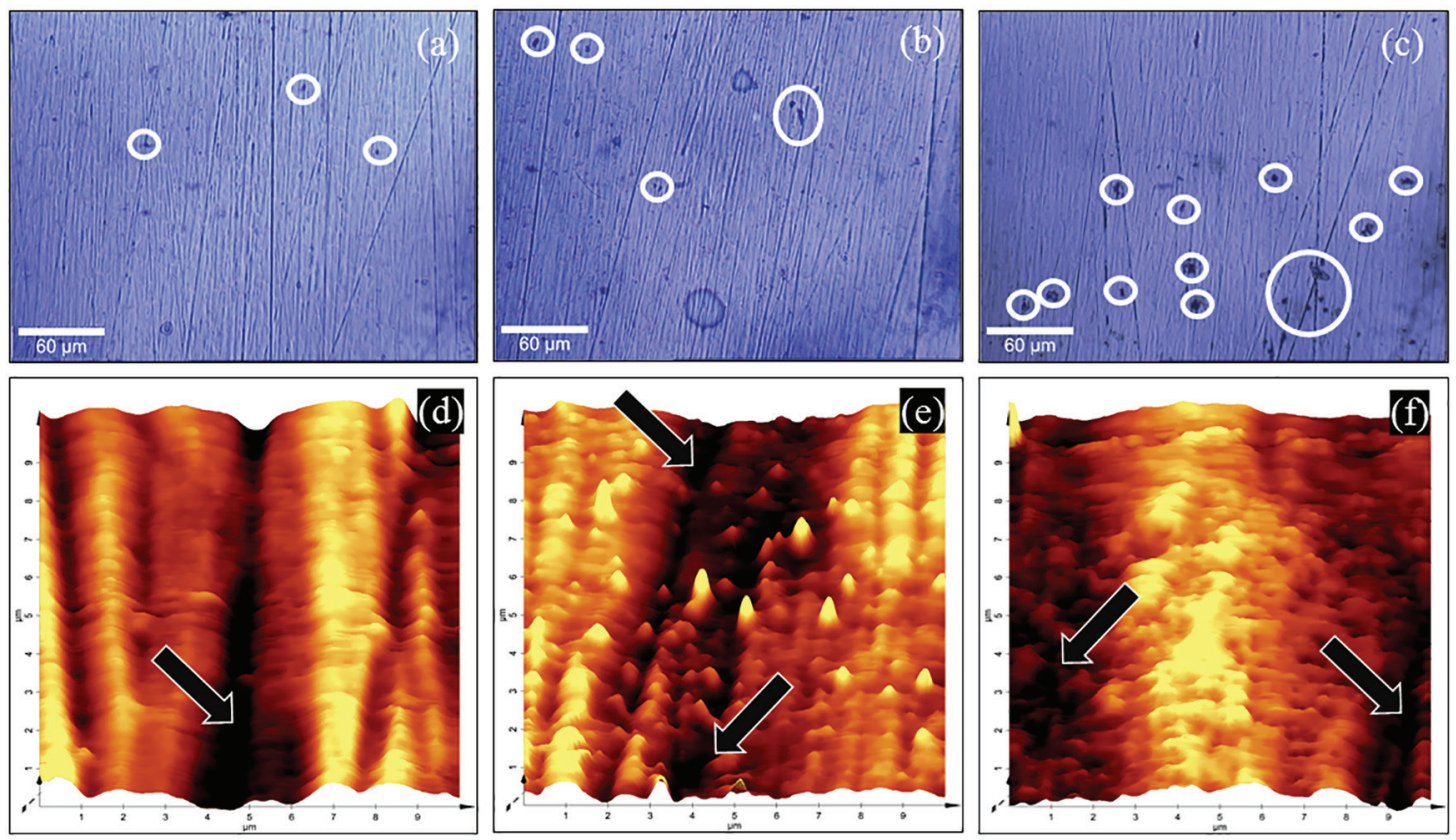

Figure 5. Optical microscopic (a-c) and atomic force microscopic (d-f) images of the AISI 1020 carbon steel coupons' surface after immersion in biodiesel/ IM (a, d), biodiesel/TBHQ (b, e) and biodiesel/PY (c, f).

with TBHQ has a small number of pits, as does the coupon immersed in biodiesel with IM. However, the coupon immersed in biodiesel with PY has pits that are greater in both number and size, indicating the low inhibition activity of PY. Fazal et al. ${ }^{46}$ found low inhibitory activity of PY when compared to benzotriazole and tert-butylamine. The AFM images in Figure 5 (d-f) reveal pit and crevice corrosion in all coupons. The coupons immersed in biodiesel with TBHQ and PY had greater values of $\mathrm{Rq}(15.6$ and $16.2 \mathrm{~nm}$, respectively) and PP (140.2 and $167.1 \mathrm{~nm}$, respectively), compared to the coupon immersed in biodiesel with IM. Based on the analysis of the images and parameters, IM had better performance as corrosion inhibitor.

\section{Antioxidant activity}

IM was expected to work as a chelator agent, reacting with metallic ions present in biodiesel media, reducting or inhibiting metal oxidative activity and increasing the IP. ${ }^{16,42}$ Figure 6 shows the IP (hours) of biodiesel free of and contamined with $200 \mathrm{ppm}$ copper(II) acetate in relation to IM concentration (ppm). Biodiesel's initial IP was $6.6 \mathrm{~h}$, and this value drops to $3.0 \mathrm{~h}$ with the contamination by copper. The initial IP value is a little bit higher than expected of soybean oil biodiesel. This can be explained by the presence of commercial antioxidants in commercial soybean oil, which do not have great influence in the experiment because IM concentrations in biodiesel were much larger and the inhibition mechanism of IM is different (metal chelation) from the inhibition mechanism of regular commercial antioxidants (radical chain-breaker). In all tested concentrations, IM increased the IP of contamined biodiesel, bringing it up to its maximum value after $5.8 \mathrm{~h}$ at a $250 \mathrm{ppm}$ concentration. Copper has great oxidative action on biodiesel. Small copper concentrations in biodiesel are more damaging than others metals, such as iron and manganese..$^{55}$

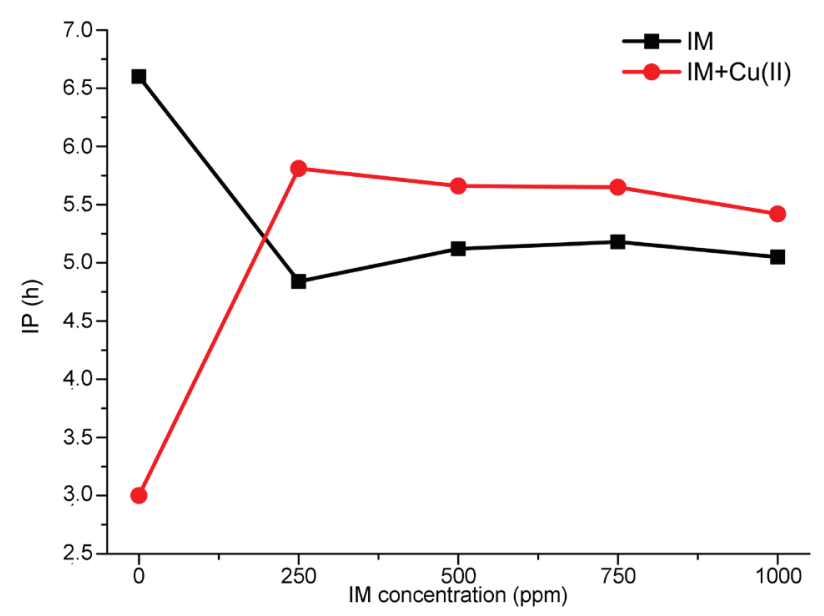

Figure 6. Influence of IM concentration on the induction period of biodiesel (black square) and on biodiesel contamined with $200 \mathrm{ppm}$ copper (red circle).

However, IM reduces the IP of contaminant-free biodiesel. It could be an indication that this compound degrades biodiesel, but IM did not increase the biodiesel medium's corrosivity during the corrosion tests, and therefore did not degrade biodiesel. In addition, the IP 
increases in contaminated biodiesel, and therefore, the oxidizing activity of copper acetate was minimized, demonstrating IM's chelator activity. The IP's reduction may be explained due to IM acting as an oxygen scavenger which would thus compete with radicals (formed by biodiesel's oxidation) for oxygen, reducing the internal pressure of the pressurized chamber, and consequently, the IP. Oxygen scavengers react with oxygen present in the medium, reducing the oxidative reactions of radicals in the propagation phase. ${ }^{3,16,42}$ Morevoer, this property influences corrosion assays, as the due reduction in oxygen decreases the rate of corrosion reactions. ${ }^{40,41}$

\section{Conclusions}

A new Schiff base compound (IM) was synthesized and characterized via spectrometric techniques. IM exhibited anticorrosion activity, according to optical, scanning electronic and atomic force microscopies microimaging analyses. Reduction in the corrosion of AISI 1020 carbon steel was observed in all tested concentrations: 250, 500, 750 and $1000 \mathrm{ppm}$. Among them, the best inhibition concentration was $750 \mathrm{ppm}$, reducing Rq from 37.8 to $11.7 \mathrm{~nm}$ and PP from 454.1 to $120.2 \mathrm{~nm}$ after 8 days of immersion. Furthermore, at a $750 \mathrm{ppm}$ concentration, IM worked better as a corrosion inhibitor than tert-butylhydroquinone and pyrogallol. The oxidation test with copper acetate suggests that IM has antioxidant activity as metal chelator and oxygen scavenger. The latter property may be responsible for reducing metal corrosion as it decreases the amount of dissolved oxygen in the medium.

\section{Supplementary Information}

Supplementary information on the FTIR infrared, ${ }^{1} \mathrm{H}$ and ${ }^{13} \mathrm{C}$ NMR spectra are available free of charge at http://jbcs.sbq.org.br as PDF file.

\section{Acknowledgments}

The authors would like to acknowledge Coordenação de Aperfeiçoamento de Pessoal de Nível Superior (CAPES), Fundação de Amparo à Pesquisa e Inovação do Espírito Santo (FAPES), and Conselho Nacional de Desenvolvimento Científico e Tecnológico (CNPq), for the financial support and fellowships granted. The authors would also like to thank Núcleo de Competências em Química do Petróleo (NCQP) for the technical support provided.

\section{References}

1. Canakci, M.; Bioresour. Technol. 2007, 98, 1167.

2. Mahmudul, H. M.; Hagos, F. Y.; Mamat, R.; Adam, A. A.; Ishak, W. F. W.; Alenezi, R.; Renewable Sustainable Energy Rev. 2017, $72,497$.

3. Yaakob, Z.; Narayanan, B. N.; Padikkaparambil, S.; Unni K., S.; Akbar P., M.; Renewable Sustainable Energy Rev. 2014, 35, 136.

4. Meher, L. C.; Sagar, D. V.; Naik, S. N.; Renewable Sustainable Energy Rev. 2006, 10, 248.

5. Choe, E.; Min, D. B.; Compr. Rev. Food Sci. Food Saf. 2006, 5 , 169.

6. Sorate, K. A.; Bhale, P. V.; Renewable Sustainable Energy Rev. 2015, 41, 777 .

7. Ahmmad, M. S.; Hassan, M. B. H.; Kalam, M. A.; Int. J. Green Energy 2018, 15, 393.

8. Fazal, M. A.; Suhaila, N. R.; Haseeb, A. S. M. A.; Rubaiee, S.; J. Cleaner Prod. 2018, 181, 508.

9. Fernandes, D. M.; Montes, R. H. O.; Almeida, E. S.; Nascimento, A. N.; Oliveira, P. V.; Richter, E. M.; Muñoz, R. A. A.; Fuel 2013, 107, 609.

10. Aquino, I. P.; Hernandez, R. P. B.; Chicoma, D. L.; Pinto, H. P. F.; Aoki, I. V.; Fuel 2012, 102, 795.

11. Cursaru, D.; Branoiu, G.; Ramadan, I.; Miculescu, F.; Ind. Crops Prod. 2014, 54, 149.

12. Sazzad, B. S.; Fazal, M. A.; Haseeb, A. S. M. A.; Masjuki, H. H.; RSC Adv. 2016, 6, 60244.

13. Kaul, S.; Saxena, R. C.; Kumar, A.; Negi, M. S.; Bhatnagar, A. K.; Goyal, H. B.; Gupta, A. K.; Fuel Process. Technol. 2007, $88,303$.

14. Aktas, D. F.; Lee, J. S.; Little, B. J.; Ray, R. I.; Davidova, I. A.; Lyles, C. N.; Suflita, J. M.; Energy Fuels 2010, 49, 2924.

15. Li, S. Y.; Kim, Y. G.; Jeon, K. S.; Kho, Y. T.; Kang, T.; Corrosion 2016, 57, 815.

16. Choe, E.; Min, D. B.; Compr. Rev. Food Sci. Food Saf. 2009, 8 , 345.

17. Varatharajan, K.; Pushparani, D. S.; Renewable Sustainable Energy Rev. 2018, 82, 2017.

18. Yildirim, A.; Çetin, M.; Corros. Sci. 2008, 50, 155.

19. Hackerman, N.; Roebuck, A. H.; J. Phys. Colloid Chem. 1951, 55,549 .

20. Schirmann, J. G.; Angilelli, K. G.; Dekker, R. F. H.; Borsato, D.; Barbosa-Dekker, A. M.; Fuel 2019, 237, 593.

21. EN 14112: Fat and Oil Derivatives. Fatty Acid Methyl Esters (FAME). Determination of Oxidation Stability (Accelerated Oxidation Test); European Committee for Standardization, Brussels, 2003.

22. Bär, F.; Hopf, H.; Knorr, M.; Krahl, J.; Fuel 2018, 215, 249.

23. ASTM D7545: Standard Test Method for Oxidation Stability of Middle Distillate Fuels - Rapid Small Scale Oxidation Test (RSSOT); ASTM International, West Conshohocken, PA, 2014. 
24. Öztürk, S.; Yildirim, A.; Çetin, M.; Tavash, M.; J. Surfactants Deterg. 2014, 17, 471.

25. Carlos, M. F. L. P.; Valbon, A.; Neves, M. A.; Santos, M. R. L.; Echevarria, A.; J. Braz. Chem. Soc. 2018, 29, 2542.

26. Negm, N. A.; El Farargy, A. F.; Al Sabagh, A. M.; Abdelrahman, N. R.; J. Surfactants Deterg. 2011, 14, 505.

27. Abdallah, Z. A.; Ahmed, M. S. M.; Saleh, M. M.; Mater. Chem. Phys. 2016, 174, 91.

28. El-Faham, A.; Osman, S. M.; Al-Lohedan, H. A.; El-Mahdy, G.; Molecules 2016, 21, 714.

29. Soltani, N.; Salavati, H.; Rasouli, N.; Paziresh, M.; Moghadasi, A.; Chem. Eng. Commun. 2016, 203, 840.

30. Benbouguerra, K.; Chafaa, S.; Chafai, N.; Mehri, M.; Moumeni, O.; Hellal, A.; J. Mol. Struct. 2018, 1157, 165.

31. Ramalingam, S.; Rajendran, S.; Ganesan, P.; Govindasamy, M.; Renewable Sustainable Energy Rev. 2018, 81, 775.

32. Singh, R. K.; Kukrety, A.; Sharma, O. P.; Poddar, M. K.; Atray, N.; Thakre, G. D.; Ray, S. S.; Waste Biomass Valorization 2016, 7, 1437.

33. Rashed, M. M.; Masjuki, H. H.; Kalam, M. A.; Alabdulkarem, A.; Rahman, M. M.; Imdadul, H. K.; Rashedul, H. K.; Renewable Energy 2016, 94, 294.

34. Yahagi, S. S.; Roveda, A. C.; Sobral, A. T.; Oliveira, I. P.; Caires, A. R. L.; Gomes, R. S.; Trindade, M. A. G.; Int. J. Anal. Chem. 2019, 2019, DOI: 10.1155/2019/6467183.

35. Deyab, M. A.; J. Taiwan Inst. Chem. Eng. 2016, 60, 369.

36. Shahid, E. M.; Jamal, Y.; Renewable Sustainable Energy Rev. 2011, 15, 4732.

37. Kumari, S.; Kumar, A.; Kumar, K. R.; Sridhar, B.; Rao, T. R.; Inorg. Chim. Acta 2009, 362, 4205.

38. Kumar, A.; Kumari, S.; Kumar, K. R.; Sridhar, B.; Rao, T. R.; Polyhedron 2008, 27, 181.

39. Cursaru, D.; Nassreddine, S.; Riachi, B.; Neagu, M.; Mihai, S.; Corros. Rev. 2018, 36, 559.

40. Meira, M.; Santana, P. M. B.; Araújo, A. S.; Silva, C. L.; Filho, J. R. L. L.; Ferreira, H. T.; Corros. Rev. 2014, 32, 143.

41. Zuleta, E. C.; Baena, L.; Rios, L. A.; Calderón, J. A.; J. Braz. Chem. Soc. 2012, 23, 2159.
42. Saluja, R. K.; Kumar, V.; Sham, R.; Renewable Sustainable Energy Rev. 2016, 62, 166.

43. Maru, M. M.; Lucchese, M. M.; Legnani, C.; Quirino, W. G.; Balbo, A.; Aranha, I. B.; Costa, L. T.; Vilani, C.; de Sena, L. Á.; Damasceno, J. C.; Fuel Process. Technol. 2009, 90, 1175.

44. Jin, D.; Zhou, X.; Wu, P.; Jiang, L.; Ge, H.; Renewable Energy 2015, 81, 457.

45. Domingos, D. V.; Tozzi, F. C.; Barros, E. V.; Pinto, F. E.; Sad, C. M. S.; Filgueiras, P. R.; Lacerda Jr., V.; Dias, H. P.; Aquije, G. M. V. F.; Romão, W.; J. Braz. Chem. Soc. 2018, 29, 2244.

46. Fazal, M. A.; Sazzad, B. S.; Haseeb, A. S. M. A.; Masjuki, H. H.; Energy Convers. Manage. 2016, 122, 290.

47. Dias, H. P.; Pereira, T. M. C.; Vanini, G.; Dixini, P. V.; Celante, V. G.; Castro, E. V. R.; Vaz, B. G.; Fleming, F. P.; Gomes, A. O.; Aquije, G. M. F. V.; Romão, W.; Fuel 2014, 126, 85.

48. Dias, H. P.; Dixini, P. V.; Almeida, L. C. P.; Vanini, G.; Castro, E. V. R.; Aquije, G. M. F. V.; Gomes, A. O.; Moura, R. R.; Lacerda, V.; Vaz, B. G.; Romão, W.; Fuel 2015, 139, 328.

49. Dias, H. P.; Barros, E. V.; Sad, C. M. S.; Yapuchura, E. R.; Gomes, A. O.; Moura, R.; Pinto, F. E.; Domingos, D. V.; Aquije, G. M. F. V.; Lacerda Jr., V.; Romão, W.; J. Braz. Chem. Soc. 2018, 29, 1690.

50. Deyab, M. A.; Keera, S. T.; J. Taiwan Inst. Chem. Eng. 2016, 68, 187.

51. Fazal, M. A.; Haseeb, A. S. M. A.; Masjuki, H. H.; Fuel Process. Technol. 2011, 92, 2154.

52. Jakeria, M. R.; Fazal, M. A.; Haseeb, A. S. M. A.; Corros. Eng., Sci. Technol. 2015, 50, 56.

53. Munoz, R. A. A.; Fernandes, D. M.; Santos, D. Q.; Barbosa, T. G. G.; Sousa, R. M. F. In Biodiesel. Feedstock, Production and Applications, $1^{\text {st }}$ ed.; Fang, Z., ed.; IntechOpen: Pequim, China, 2011, ch. 6.

54. Jain, S.; Sharma, M. P.; Fuel 2013, 109, 379.

55. Jain, S.; Sharma, M. P.; Fuel 2011, 90, 2045.

Submitted: June 26, 2019

Published online: September 9, 2019 